\title{
Persistent organic pollutant levels in human visceral and subcutaneous adipose tissue in obese individuals-Depot differences and dysmetabolism implications
}

\author{
Diogo Pestana, Gil Faria, Carla Sá, Virgínia C. Fernandes, Diana Teixeira, Sónia \\ Norberto, Ana Faria, Manuela Meireles, Cláudia Marques, \\ Luísa Correia-Sá, Ana Cunha, João T. Guimarães, António Taveira-Gomes, Ana \\ Cristina Santos, Valentina F. Domingues, Cristina Delerue-Matos, \\ Rosário Monteiro, Conceição Calhau
}

\begin{abstract}
Background: The role of persistent organic pollutants (POPs) with endocrine disrupting activity in theaetiology of obesity and other metabolic dysfunctions has been recently highlighted. Adipose tissue (AT) is acommon site of POPs accumulation where they can induce adverse effects on human health.

Objectives: To evaluate the presence of POPs in human visceral (vAT) and subcutaneous (scAT) adipose tissue in a sample of Portuguese obese patients that underwent bariatric surgery, and assess their putative association with metabolic disruption preoperatively, as well as with subsequent body mass index (BMI) reduction.

Methods: AT samples $\left(n^{1} 1 / 4189\right)$ from obese patients (BMI Z35) were collected and the levels of 13 POPs weredetermined by gas chromatography with electroncapture detection (GC-ECD). Anthropometric and biochem-ical data were collected at the time of surgery. BMI variation was evaluated after 12 months and adipocyte sizewas measured in AT samples.

Results: Our data confirm that POPs are pervasive in this obese population ( $96.3 \%$ of detection on both tissues),

their abundance increasing with age $\left(R_{S}^{1 / 4} 0.310, p \mathbf{O} 0.01\right)$ and duration of obesity $\left(R_{S} 1 / 40.170, p \mathbf{O} 0.05\right)$. We observed a difference in AT depot POPs storage capability, with higher levels of $\Sigma$ POPs in vAT (213.97204.2 compared to $155.17147 .4 \mathrm{ng} / \mathrm{g}$ of fat, $p \mathbf{O} 0.001$ ), extremely relevant when evaluating their metabolic impact.

Furthermore, there was a positive correlation between POP levels and the presence of metabolic syndrome components, namely dysglycaemia and hypertension, and more importantly with cardiovascular risk $\left(R_{S} 1 / 40.277, p \mathbf{O} 0.01\right)$, with relevance for vAT $\left(R_{S} 1 / 40.315, p \mathbf{O} 0.01\right)$. Finally, we observed an interesting relation of higher POP levels with lower weight loss in older patients.

Conclusion: Our sample of obese subjects allowed us to highlight the importance of POPs stored in AT on thedevelopment of metabolic dysfunction in a context of obesity, shifting the focus to their metabolic effects andnot only for their recognition as environmental obesogens.
\end{abstract}

Keywords: Adipose tissue, Bariatric surgery, Metabolic syndrome, Obesity, Persistent organicpollutants

Abbreviations: persistent organic pollutants, POPs; adipose tissue, AT; visceral adipose tissue, vAT; subcutaneous adipose tissue, scAT; metabolic syndrome, MetS; cardiovascular diseases, CVD; type 2 diabetes mellitus, T2DM; body mass index, BMI

\section{Introduction}

Central obesity is considered by some authors as a crucial component in the causal pathway of the metabolic syndrome (Palaniappan et al., 2004). The aetiology of obesity is multifactorial, but whereas energy imbalance is mandatory, many agents may 

contribute to its establishment, including genetic and behavioural/ environmental factors (Newbold et al., 2008). Environmental conditions involving exposure to chemicals that even at very low doses have endocrine disruption effects, mimicking endogenous hormones or modulating transcription factors, epigenetic mechanisms and endogenous hormone kinetics/availability, are proposed for a number of adverse human health effects, including infertility and cancers (Vandenberg et al., 2012, 2013; Valera et al., 2013; Sjoberg Lind et al., 2013).

Recent data correlated synthetic chemical production with obesity and diabetes prevalence (Baillie-Hamilton, 2002; Neel and Sargis, 2011). These man-made chemicals are environmentally persistent since they have an intrinsic resistance to natural degradation processes, are lipophilic and bioaccumulate in the food chain, being classified as persistent organic pollutants (POPs). Humans typically accumulate the highest POP concentrations in the adipose tissue (AT) (Ozonoff et al., 1994; Li et al., 2006).

Considering the endocrine function of adipocytes and knowing that exposure to these chemicals disrupts normal development and homeostasis, resulting in obesity, these chemicals were termed environmental "obesogens" (Baillie-Hamilton, 2002; Grun and Blumberg, 2006). Hence, there is a growing concern over a background exposure to POPs and the prevalence of metabolic syndrome (MetS), namely by the synergistic and simultaneous exposure to mixtures of POPs. These findings raise the possibility that, in addition to obesity itself, some POPs stored in AT may be key to the pathogenesis of the MetS (Lee, 2007) especially when it remains puzzling why some people are more susceptible to develop MetS features or successful in losing weight (Freedland, 2004). Visceral and subcutaneous adipose tissues (vAT and scAT) display different metabolic properties, the first being a highly metabolically active tissue and apparently more susceptible to lipolysis (Freedland, 2004; Preis et al., 2010). Despite these differences, their putative dissimilar POPs storage capability and subsequent implications are still under discussion as duly raised by La Merrill et al. (2013) and other recent studies, however still with some restraints and insufficient to conclude this discussion (Malarvannan et al., 2013; Kim et al., 2014).

This study aimed to answer some of this issues, evaluating in a sample of Portuguese obese patients undergoing bariatric surgery, the levels of POPs in AT depots as well as their possible association with MetS comorbidities before surgery. In addition, we evaluated the relationship with the subsequent body mass index (BMI) reduction 12 months after surgery. For this purpose, we measured the levels of various POPs in two AT depots (vAT and scAT) and evaluated the relationships with MetS components and a variety of biological and clinical parameters preoperatively.

1. Materials and methods

1.1. Study subjects

A cohort of 189 obese men and women undergoing bariatric surgery for weight reduction at the General Surgery Department, S. João Hospital (Porto, Portugal), was recruited between January 2010 and June 2011. Patients met the criteria for obesity surgery [including BMI Z $40 \mathrm{~kg} / \mathrm{m}^{2}$, or $\mathbf{Z} 35 \mathrm{~kg} / \mathrm{m}^{2}$ with at least one comorbidity (hypertension, type 2 diabetes (T2DM), dyslipidaemia, or obstructive sleep apnoea syndrome)] and signed informed consent to participate in the study. The study protocol was approved by the Hospital's Ethics Committee. Data regarding socio-demographic characteristics, clinical history, life-style factors, parity and occupation were collected from the hospital Medical Support System. Level of education was recorded as years of education, and then classified into four levels. Place of residence was defined according to the Eurostat degree of urbanization classification nomenclature (2011) into three categories (Eurostat, 2012). In turn, the subjects occupation was defined according to the Portuguese Occupation classification nomenclature (Instituto Nacional de Estatística, 2011), and was subsequently classified into three levels of occupation: white-collar (classes 0-4), blue-collar (classes 5-9) and without job (students and retired subjects).

\subsection{Clinical and biochemical parameters}

Anthropometrics, adiposity-related markers and various clinical variables were measured preoperatively. BMI $\left(\mathrm{kg} / \mathrm{m}^{2}\right)$ was calculated both at baseline and 12 months post-surgery. Blood samples were collected after an overnight fast and measures of insulin resistance (HOMA-IR) and beta-cell function (HOMA-B) were calculated with the homeostatic model assessment (HOMA2) (Wallace et al., 2004) Routine serum chemistries were measured using conventional methods with an Olympus AU5400 $\mathbf{s}$ automated clinical chemistry analyser (Beckman-Coulter ${ }^{\mathbf{s}}$, Izasa, Porto, Portugal). Low-density lipoprotein (LDL) cholesterol was calculated according to Friedewald's equation (Friedewald et al., 1972). Insulin was measured by an electrochemiluminescent immunoassay using a Cobas ${ }^{\mathbf{s}}$ e411 automated analyzer (Roche ${ }^{\mathbf{s}}$, Lisbon, Portugal) and glycated haemoglobin (HbA1c) was measured with an ion-exchange HPLC system with a D-10 ${ }^{\text {rM }}$ Bio-Rad $^{\text {s }}$ analyzer (Bio-Rad ${ }^{\text {s, }}$ Porto, Portugal).

The MetS components were classified according to the Harmonized Criteria (Alberti et al., 2009) that defined subjects with three or more of the following criteria as having MetS: (a) abdominal obesity (waist circumference $Z 102 \mathrm{~cm}$ for men and 88 for women); (b) high triglycerides (Z150 mg/dL); (c) low HDL cholesterol ( o $40 \mathrm{mg} / \mathrm{dL}$ in men and o $50 \mathrm{mg} / \mathrm{dL}$ in women); (d) high blood pressure ( $Z$ 130/85 mmHg); and (e) high fasting glucose (Z100 mg/dL). Treatment for any of these conditions was also considered a positive result. Lastly, we used the Framingham risk score to estimate the 10-year cardiovascular risk of these subjects (D'Agostino et al., 2008).

\subsection{Chemicals and reagents}

Formaldehyde 37\%, xylol, entellan, hematoxylin, eosin and paraffin were obtained from Merck ${ }_{s}^{s}$ (Darmastadt, Germany). Ethanol solution (EtOH) was obtained from Panreac (Barcelona, Spain) and $n$-hexane was purchased from Sigma-Aldrich $^{\mathbf{s}}$ (Madrid, Spain). The POPs aldrin, dieldrin and endrin were obtained from Pestanal Fluka ${ }^{\mathbf{s}}$ (Madrid, Spain), hexachlorobenzenene (HCB) and hexachlorocyclohexane lindane (HCH Lindane) were obtained from Pestanal Riedel-de Haën $^{\mathbf{s}}$ (Madrid, Spain), $\Sigma$ hexachlorocyclohexane (sum of $\alpha-\mathrm{HCH}, \beta-\mathrm{HCH}$ and $\delta-\mathrm{HCH}$ ) was obtained from Sigma-Aldrich ${ }^{\mathbf{S}}$ (Madrid, Spain). Endosulfan I, endosulfan II, methoxyclor, 2,3,7,8-tetrachlorodibenzodioxin (TCDD), $p, p^{0}$-dichlorodiphenyldichloroethane $\left(p, p^{0}\right.$-DDD) and $p, p^{\prime}$-dichlorodiphenyltrichloroethane $\left(o, p^{0}\right.$-DDT) were obtained from Supelco ${ }^{\mathbf{S}}$ (Madrid, Spain). $p, p^{0}$-dichlorodiphenyldichloroethylene ( $p, p^{0}$-DDE), was obtained from Chem Services (West Chester, United States of America (USA)).

\subsection{Adipose tissue sampling}

Human AT samples from two different depots were collected during bariatric surgery: vAT corresponded to omental fat and scAT to subcutaneous abdominal fat. After being excised, AT samples were coded, processed and divided into different portions and stored at $-801 \mathrm{C}$

\subsection{Adipocyte size measurement}

A small portion of both ATs was fixed in buffered formaldehyde $10 \%$, for at least $48 \mathrm{~h}$ ( 4 1 C). Following fixation, the AT was dehydrated and finally embedded in paraffin. All samples were coded for a blind analysis and $3 \mathrm{~mm}$-thick sections were obtained with a Leicas ${ }^{\mathbf{S}}$ Microtome (RM2125RT, Lisbon, Portugal), and stained with hematoxylin and eosin to assess morphology. Digital images were acquired with a fluorescence microscope (Nikon Eclipse 50i ${ }^{\text {s }}$, Melville, USA), at a magnification of $\times 200$ from five randomly-selected different optical fields. Adipocyte area measurement was performed with ImajeJ software ${ }^{\mathbf{s}}$ (National Institute of Health, Bethesda, USA).

\subsection{Determination of POPs in the AT}

POP analysis was performed according to the method described by Fernandes et al. (2012). The procedure included standardized extraction of $200 \mathrm{mg}$ of AT, clean up using solid phase extraction columns Strata C18-E (SPE, $500 \mathrm{mg} / 3 \mathrm{~mL}, 55 \mathrm{~mm}$ ), purchased from Phenomenex (Torrance, CA, USA) and quantification by gas chromatography with electron-capture detection (GC-ECD) a Shimadzu GC-2010, equipped with a capillary column of $30 \mathrm{~m}$ ZB-XLB $(0.25 \mathrm{~mm}$ i.d. $0.25 \mu \mathrm{m}$ film thickness, Zebron-Phenomenex). 4-4-dichlorobenzophenone was used as internal standard. The results were expressed as ng of POPs/g of fat and are a mean of three individual determinations of the same sample.

\subsection{Statistical analysis}

Standard descriptive statistics was used to describe the AT POP levels. Due to the lack of normal distribution, data were described as frequencies, median and respective interquartile range (IQR). The association between POPs concentration in 
AT and various parameters was analysed computing Spearman correlation coefficients, applied the Bonferroni multiple testing correction test when evaluating the effects of different POPs (significance level was considered for $p$ values $\mathbf{0} 0.001$ ). The Mann-Whitney, Kruskal-Wallis and Wilcoxon tests were used to compare median of POPs between groups. Additionally, $t$ test was used to compare adipocyte area means in vAT and scAT and BMI variation between age groups. All probabilities were two-tailed and $p$ values $\mathbf{0} 0.05$ were regarded as significant. All statistical analyses were performed using Statistical Package for Social Sciences (SPSS, 18.0 version statistical software, IBM Corp. ${ }^{\mathbf{s}}$, New York, USA).

\section{Results}

\subsection{Descriptive characteristics}

The sociodemographic and lifestyle characteristics of the patients are shown in Supplementary material, Table S1. These 189 patients with an age range of 19-65 years (mean age of 42.5710 .9 years) included 166 females (88.7\%). Among females, $76.5 \%$ had children, being the mean number of children 1.671 .1 . Approximately half of the patients lived in highly populated areas in the north region of Portugal and at the moment of surgery the mean BMI was $44.875 .0 \mathrm{~kg} / \mathrm{m}^{2}$. Regarding other considered characteristics, half of the subjects had 5-9 years of education or less (33.9\% and $21.7 \%$, respectively) and blue-collar occupation (43.4\%). Concerning lifestyles, most of the subjects did not consume alcoholic beverages or smoked $(66.1 \%$ and $75.2 \%$, respectively).

\subsection{Distinct distribution of POP levels in vAT and scAT}

We examined the presence of the 13 tested POPs both in vAT and scAT samples (Table 1). After observing similar POPs distribution between genders (data not shown), and due to the small number of male subjects, data was analysed without taking into account the gender. In both tissues, the percentage of samples with detectable concentrations of POPs was $96.3 \%$, with median values of 172.9 (IQR 219.9) $\mathrm{ng} / \mathrm{g}$ of fat in vAT and 116.1 (IQR 156.6) $\mathrm{ng} / \mathrm{g}$ of fat in scAT, showing that virtually all patients had detectable quantities of these pollutants in the AT.

The most ubiquitous detected POPs, the $\Sigma \mathrm{HCH}$, appeared in $91.5 \%$ and $89.9 \%$ of patients in the vAT and scAT with median values of 103.7 (IQR 147.2) ng/g of fat and 65.2 (IQR 145.4) ng/g of fat, respectively. With another distribution pattern, endosulfan II and methoxychlor were present unevenly in both AT types, detected in
$28.0 \%$ and $61.9 \%$ of vAT samples, but only in $11.1 \%$ and $19.0 \%$ of scAT samples. Regarding DDT and its metabolites, the percentage of positive samples for this family of pesticides was $50.8 \%$ in both AT types. The highest contribution to their overall contamination came from the metabolite $p, p^{0}-\mathrm{DDE}$, found in $29.1 \%$ of vAT and $33.3 \%$ of scAT samples, respectively with 22.6 (IQR 61.5 ) $\mathrm{ng} / \mathrm{g}$ of fat and 2.8 (IQR 10.3) $\mathrm{ng} / \mathrm{g}$ of fat.

To compare the vAT and scAT putative dissimilar POPs distribution, POP levels present simultaneously in the two ATs of the same patient were compared (Table 2). The levels of $\Sigma$ POPs were positively correlated between both $\mathrm{ATs}\left(R_{S} 1 / 40.632, p \mathbf{0} 0.01\right)$, but the concentration in vAT was significantly higher (213.97204.2 compared to $155.17147 .4 \mathrm{ng} / \mathrm{g}$ of fat, $p \mathbf{O} 0.001)$. Regarding the evaluated POPs, $\Sigma$ HCH, HCB, endosulfan II, dieldrin and methoxychlor were positively correlated between vAT and scAT. On the other hand, when comparing the absolute concentration in each AT, higher concentrations of $\Sigma \mathrm{HCH}, \Sigma \mathrm{DDT} / \mathrm{DDE} / \mathrm{DDD}, p, p^{0}-\mathrm{DDE}$ and $p, p^{0}$-DDD were observed in vAT, contrasting with lower concentrations of $\mathrm{HCB}$, aldrin and dieldrin.

\subsection{POP levels were associated with preoperative clinical and biochemical parameters of metabolic dysfunction}

The association between POP levels and the patient's clinical and biochemical parameters at baseline is presented in Table 3 . The total $\Sigma$ POPs concentration in each subject was positively correlated with age, years of obesity evolution, HbA1c, urea and systolic blood pressure. The observed correlations were similar when considering the $\Sigma$ POPs in vAT, however in scAT no correlation was found with obesity evolution and urea. Instead, $\Sigma$ POPs in scAT were positively correlated with HOMA-IR and diastolic blood pressure. The same analysis was conducted regarding the individual POPs (see Supplementary material, Tables S2 and S3). Among them, we emphasize the positive correlation of methoxychlor vAT levels with age, LDL cholesterol, glycaemia, HbA1c, ALT and urea and of $p, p^{0}$-DDE with age and glucose metabolism, namely with HbA1c. Additionally, we examined the association between POP levels and adipocyte size. The mean adipocyte size in scAT $\left(632171501 \mathrm{~mm}^{2}\right)$ was significantly higher compared to vAT (420671296 $\mathrm{mm}^{2}$; o 0 0.0001) (see Supplementary material, Fig. S1). No significant correlation was found between the $\Sigma$ POPs levels and adipocyte size from the corresponding tissues.

Table 1

Detection of studied persistent organic pollutants (POPs) in visceral and subcutaneous adipose tissue (vAT and scAT) of the 189 patients.

\begin{tabular}{|c|c|c|c|c|c|c|c|c|c|}
\hline POPs vAT & $n$ & $\%^{\mathrm{a}}$ & Median $^{b}$ & $\mathrm{IQR}^{\mathrm{b}}$ & POPs scAT & $n$ & $\%^{\mathrm{a}}$ & Median $^{b}$ & $\mathrm{IQR}^{\mathrm{b}}$ \\
\hline$\Sigma \mathrm{HCH}$ & 173 & 91.5 & 103.7 & 147.2 & $\Sigma \mathrm{HCH}$ & 170 & 89.9 & 65.2 & 145.4 \\
\hline $\mathrm{HCH}$ Lindane & 44 & 23.3 & 19.0 & 29.5 & HCH Lindane & 36 & 19.0 & 31.0 & 36.9 \\
\hline $\mathrm{HCB}$ & 18 & 9.5 & 64.7 & 30.7 & $\mathrm{HCB}$ & 17 & 9.0 & 72.2 & 30.4 \\
\hline Aldrin & 34 & 18.0 & 7.2 & 9.9 & Aldrin & 30 & 15.9 & 22.7 & 32.9 \\
\hline Dieldrin & 30 & 15.9 & 65.2 & 89.9 & Dieldrin & 26 & 13.8 & 45.1 & 96.9 \\
\hline Endrin & 6 & 3.2 & 284.8 & 322.7 & Endrin & 2 & 1.1 & 146.4 & \\
\hline Endosulfan I & 14 & 7.4 & 2.8 & 2.7 & Endosulfan I & 6 & 3.2 & 47.0 & 94.3 \\
\hline Endosulfan II & 53 & 28.0 & 1.8 & 2.2 & Endosulfan II & 21 & 11.1 & 2.2 & 18.2 \\
\hline TCDD & 3 & 1.6 & 23.8 & & TCDD & 6 & 3.2 & 24.6 & 29.7 \\
\hline Methoxychlor & 117 & 61.9 & 21.3 & 31.6 & Methoxychlor & 36 & 19.0 & 40.6 & 45.8 \\
\hline$\Sigma \mathrm{DDT} / \mathrm{DDE} / \mathrm{DDD}$ & 96 & 50.8 & 40.8 & 51.1 & $\Sigma \mathrm{DDT} / \mathrm{DDE} / \mathrm{DDD}$ & 96 & 50.8 & 5.7 & 29.3 \\
\hline$o, p^{0}-\mathrm{DDT}$ & 19 & 10.1 & 41.7 & 6.5 & $o, p^{0}-\mathrm{DDT}$ & 19 & 10.1 & 39.7 & 16.2 \\
\hline$p, p^{0}-\mathrm{DDE}$ & 55 & 29.1 & 22.6 & 61.5 & $p, p^{0}-\mathrm{DDE}$ & 63 & 33.3 & 2.8 & 10.3 \\
\hline$p, p^{0}-\mathrm{DDD}$ & 24 & 12.7 & 58.6 & 77.1 & $p, p^{0}-\mathrm{DDD}$ & 18 & 9.5 & 15.5 & 94.9 \\
\hline$\Sigma$ POPs in vAT & 182 & 96.3 & 172.9 & 219.9 & $\Sigma$ POPs in scAT & 182 & 96.3 & 116.1 & 156.6 \\
\hline Total $\Sigma$ POPs & 189 & 100.0 & 290.5 & 372.2 & Maximum $^{\mathrm{b}}$ & 1668.3 & Minimum $^{\mathrm{b}}$ & 5.3 & \\
\hline
\end{tabular}

\footnotetext{
${ }^{\text {a }}$ Percentage of the total number of positive samples.
}

${ }^{\mathrm{b}} \mathrm{ng} / \mathrm{g}$ of fat; interquartile range (IQR). 
Table 2

Comparison between levels of persistent organic pollutants (POPs) present simultaneously in both visceral (vAT) and subcutaneous adipose tissue (scAT).

\begin{tabular}{|c|c|c|c|c|c|c|}
\hline \multirow[t]{2}{*}{ POPs } & \multirow{2}{*}{$\begin{array}{l}n \\
\text { (vAT and scAT) }\end{array}$} & \multirow[t]{2}{*}{$\%^{\mathrm{a}}$} & \multirow[t]{2}{*}{ Spearman's correlation } & \multicolumn{2}{|c|}{ vAT vs. scAT (Wilcoxon test) } & \multirow[b]{2}{*}{$p$ Value } \\
\hline & & & & vAT $\left(\right.$ Mean 7SD) ${ }^{\mathrm{b}}$ & scAT $\left(\right.$ Mean 7SD) ${ }^{\mathrm{b}}$ & \\
\hline$\Sigma \mathrm{HCH}$ & 155 & 82.0 & $0.540^{\mathrm{nn}}$ & 121.17103 .8 & 95.5786 .6 & $0.003^{n}$ \\
\hline $\mathrm{HCH}$ lindane & 20 & 10.6 & -0.074 & 35.9774 .6 & 50.2757 .7 & 0.067 \\
\hline $\mathrm{HCB}$ & 17 & 9.0 & $0.669^{\mathrm{nn}}$ & 74.9731 .0 & 83.1730 .7 & $0.028^{n}$ \\
\hline Aldrin & 23 & 12.2 & 0.369 & 12.0711 .4 & 23.9725 .3 & $0.008^{n}$ \\
\hline Dieldrin & 14 & 7.4 & $0.829^{\mathrm{nn}}$ & 71.3767 .4 & 111.7792 .7 & $0.006^{n}$ \\
\hline Endosulfan II & 21 & 11.1 & $0.714^{\mathrm{nn}}$ & 54.87116 .3 & 60.27131 .8 & 0.054 \\
\hline Methoxychlor & 30 & 15.9 & $0.372^{\mathrm{n}}$ & 32.4718 .5 & 33.9723 .1 & 0.704 \\
\hline$\Sigma \mathrm{DDT} / \mathrm{DDE} / \mathrm{DDD}$ & 51 & 27.0 & 0.099 & 62.2768 .7 & 36.9755 .2 & $0.023^{n}$ \\
\hline$o, p^{0}-\mathrm{DDT}$ & 18 & 9.5 & -0.071 & 42.479 .5 & 39.3713 .6 & 0.420 \\
\hline$p, p^{0}-\mathrm{DDE}$ & 18 & 9.5 & 0.426 & 72.47108 .9 & 18.5726 .7 & $0.039^{n}$ \\
\hline$p, p^{0}-\mathrm{DDD}$ & 12 & 6.3 & 0.112 & 85.7733 .3 & 35.9752 .1 & $0.023^{n}$ \\
\hline$\Sigma$ POPs & 175 & 92.6 & $0.632^{\mathrm{nn}}$ & 213.97204 .2 & 155.17147 .4 & ro.001 $1^{\mathrm{nn}}$ \\
\hline
\end{tabular}

${ }^{\text {a }}$ Percentage of the total number of positive samples in both AT-positive samples.

${ }^{\mathrm{b}} \mathrm{ng} / \mathrm{g}$ of fat; standard deviation (SD). Statistical analysis with Spearman's correlation and Wilcoxon test.

${ }^{\mathrm{n}} \mathrm{p} 00.05$.

${ }^{\mathrm{nn}} \mathrm{p} 00.01$

Table 3

Clinical and biological characteristics of subjects at baseline and their correlation with sum of persistent organic pollutant ( $\Sigma$ POP) levels in total, visceral (vAT) and subcutaneous adipose tissue (scAT).

\begin{tabular}{|c|c|c|c|c|c|}
\hline Parameters & $n$ & Mean7SD & $\Sigma$ POPs vAT & $\Sigma \mathrm{POPs} \mathrm{scAT}$ & Total $\Sigma$ POPs \\
\hline \multicolumn{6}{|l|}{ Age information } \\
\hline Age (years) & 189 & 42.5710 .9 & $0.344^{\mathrm{nn}}$ & $0.245^{\mathrm{nn}}$ & $0.310^{\mathrm{nn}}$ \\
\hline Obesity evolution (years) & 180 & 19.179 .7 & $0.177^{\mathrm{n}}$ & 0.085 & $0.170^{\mathrm{n}}$ \\
\hline \multicolumn{6}{|l|}{ Anthropometric parameters } \\
\hline $\mathrm{BMI}\left(\mathrm{kg} / \mathrm{m}^{2}\right)$ & 189 & 44.875 .0 & 0.039 & 0.041 & 0.045 \\
\hline Waist circunference $(\mathrm{cm})$ & 158 & 123.0713 .2 & -0.002 & 0.097 & 0.031 \\
\hline vAT adipocyte area $\left(\mathrm{mm}^{2}\right)$ & 183 & 4218.071308 .0 & 0.014 & & 0.040 \\
\hline scAT adipocyte area $\left(\mathrm{mm}^{2}\right)$ & 182 & 6312.071508 .0 & & 0.060 & 0.074 \\
\hline \multicolumn{6}{|l|}{ Plasma lipid profile } \\
\hline Total cholesterol (mg/dL) & 189 & 205.3740 .1 & 0.143 & 0.078 & 0.096 \\
\hline Total triglycerides $(\mathrm{mg} / \mathrm{dL})$ & 189 & 136.2761 .0 & 0.055 & 0.068 & 0.052 \\
\hline HDL cholesterol (mg/dL) & 189 & 50.8711 .8 & 0.044 & 0.031 & 0.045 \\
\hline LDL cholesterol (mg/dL) & 189 & 132.3732 .1 & 0.100 & 0.095 & 0.091 \\
\hline \multicolumn{6}{|c|}{ Plasma glucose homeostasis and insulin sensitivity } \\
\hline Glycaemia $(\mathrm{mg} / \mathrm{dL})$ & 189 & 100.1728 .1 & 0.098 & 0.104 & 0.109 \\
\hline HbA1c (\%) & 183 & 5.870 .9 & $0.313^{n n}$ & $0.249^{\mathrm{nn}}$ & $0.279^{\mathrm{nn}}$ \\
\hline HOMA-IR & 165 & 2.571 .6 & -0.042 & $0.174^{\mathrm{n}}$ & 0.053 \\
\hline HOMA2-B (\%) & 165 & 156.6768 .7 & -0.136 & 0.084 & -0.034 \\
\hline \multicolumn{6}{|l|}{ Blood pressure } \\
\hline Systolic blood pressure (mmHg) & 148 & 136.6718 .3 & $0.178^{\mathrm{n}}$ & $0.209^{n}$ & $0.176^{\mathrm{n}}$ \\
\hline Diastolic blood pressure ( $\mathrm{mmHg}$ ) & 148 & 82.7713 .2 & 0.078 & $0.198^{n}$ & 0.123 \\
\hline \multicolumn{6}{|l|}{ Cell damage markers } \\
\hline $\operatorname{AST}(\mathrm{U} / \mathrm{L})$ & 184 & 25.8711 .0 & -0.007 & -0.014 & 0.014 \\
\hline $\mathrm{ALT}(\mathrm{U} / \mathrm{L})$ & 185 & 29.2717 .4 & 0.059 & 0.080 & 0.086 \\
\hline gGT (U/L) & 182 & 38.3735 .1 & 0.080 & 0.026 & 0.069 \\
\hline $\mathrm{ALP}(\mathrm{U} / \mathrm{L})$ & 189 & 71.4720 .2 & 0.031 & -0.024 & 0.023 \\
\hline \multicolumn{6}{|l|}{ Others parameters } \\
\hline Urea $(\mathrm{g} / \mathrm{L})$ & 189 & 34.579 .6 & $0.248^{\mathrm{nn}}$ & 0.124 & $0.199^{\mathrm{nn}}$ \\
\hline C-reactive protein $(\mathrm{mg} / \mathrm{L})$ & 120 & 11.678 .5 & 0.012 & -0.067 & -0.031 \\
\hline
\end{tabular}

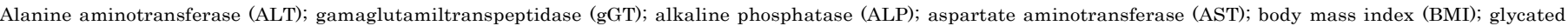
haemoglobin (HbA1c); insulin resistance (HOMA-IR); beta-cell function (HOMA-B); standard deviation (SD). Statistical analysis with Spearman's correlation.

${ }^{\mathrm{n}} \mathrm{p} 00.05$.

${ }^{\mathrm{nn}} \mathrm{p} 00.01$

The relationship between POP levels and the prevalence of individual metabolic abnormalities and MetS in the patients was also assessed (Table 4). MetS was present in $65.8 \%$ of subjects. As for its components, $45.9 \%$ had high triglycerides, $54.6 \%$ reduced HDL cholesterol, $36.5 \%$ elevated fasting glucose and $79.5 \%$ had high blood pressure. Comparing the $\Sigma$ POP levels of patients with or without these metabolic abnormalities, we observed that the levels either for total or both AT types tended to be higher in those with metabolic dysfunction. This difference was significant for dysglycaemia, with particular emphasis for vAT $\Sigma$ POPs ( $p$ 1/4 0.001). Despite with a similar pattern, the difference in elevated blood pressure and MetS itself was not significant for

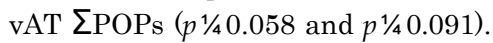

Considering the number of MetS components present in each patient, the pattern of POPs distribution was once more different, especially for vAT $\Sigma$ POPs where the patients with more MetS 
Table 4

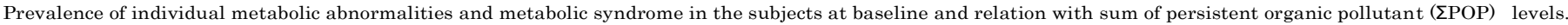

\begin{tabular}{|c|c|c|c|c|c|c|c|c|c|c|}
\hline \multirow[t]{2}{*}{ Characteristics } & \multirow[t]{2}{*}{$n(\%)$} & \multicolumn{3}{|c|}{$\Sigma$ POPs vAT } & \multicolumn{3}{|c|}{$\Sigma \mathrm{POPs}$ scAT } & \multicolumn{3}{|c|}{ Total $\Sigma$ POPs } \\
\hline & & Median $^{a}$ & $\mathrm{IQR}^{\mathrm{a}}$ & $p$ Value & Median $^{a}$ & $\mathrm{IQR}^{\mathrm{a}}$ & $p$ Value & Median $^{a}$ & $\mathrm{IQR}^{\mathrm{a}}$ & $p$ Value \\
\hline \multicolumn{4}{|c|}{ Elevated triglycerides } & 0.119 & & & 0.220 & & & 0.245 \\
\hline With & $84(45.9)$ & 180.0 & 221.7 & & 150.6 & 174.6 & & 303.9 & 364.3 & \\
\hline Without & $99(54.1)$ & 159.9 & 208.5 & & 98.6 & 149.7 & & 222.4 & 372.1 & \\
\hline \multicolumn{4}{|l|}{ Reduced HDL } & 0.257 & & & 0.479 & & & 0.308 \\
\hline With & $100(54.6)$ & 176.6 & 211.0 & & 153.0 & 173.4 & & 305.2 & 388.7 & \\
\hline Without & $83(45.4)$ & 169.8 & 192.6 & & 100.4 & 157.0 & & 268.2 & 354.9 & \\
\hline \multicolumn{4}{|c|}{ Elevated fasting glucose } & $0.001^{\mathrm{nn}}$ & & & $0.022^{n}$ & & & $0.002^{\mathrm{n}}$ \\
\hline With & $69(36.5)$ & 223.3 & 270.7 & & 162.4 & 187.2 & & 356.7 & 445.2 & \\
\hline Without & $120(63.5)$ & 140.6 & 189.2 & & 95.3 & 146.1 & & 220.4 & 380.2 & \\
\hline \multicolumn{4}{|c|}{ Elevated blood pressure } & 0.058 & & & 0.107 & & & 0.088 \\
\hline With & $132(79.5)$ & 182.6 & 215.5 & & 127.7 & 163.2 & & 300.7 & 366.1 & \\
\hline Without & $34(20.5)$ & 118.6 & 202.8 & & 65.1 & 165.6 & & 182.6 & 352.5 & \\
\hline \multicolumn{4}{|c|}{ Metabolic syndrome } & 0.091 & & & 0.248 & & & 0.142 \\
\hline With & $121(65.8)$ & 179.1 & 210.7 & & 139.9 & 162.9 & & 299.0 & 377.8 & \\
\hline Without & $63(34.2)$ & 140.6 & 233.8 & & 98.7 & 151.6 & & 202.5 & 368.1 & \\
\hline \multicolumn{4}{|c|}{ Number of components } & $0.008^{n}$ & & & 0.111 & & & $0.026^{n}$ \\
\hline 1 & $17(9.2)$ & 138.1 & 133.5 & & 99.8 & 145.2 & & 213.1 & 302.8 & \\
\hline 2 & $46(25.0)$ & 139.9 & 252.6 & & 85.5 & 152.8 & & 199.4 & 394.9 & \\
\hline 3 & $53(28.8)$ & 133.4 & 203.6 & & 69.0 & 151.3 & & 222.4 & 444.8 & \\
\hline 4 & $44(23.9)$ & 194.8 & 233.6 & & 134.8 & 143.3 & & 303.7 & 268.3 & \\
\hline 5 & $24(13.0)$ & 293.6 & 265.8 & & 180.1 & 291.9 & & 419.1 & 606.2 & \\
\hline
\end{tabular}

${ }^{\mathrm{n}} p 00.05$.

${ }^{\mathrm{nn}} \mathrm{p} 00.01$.

${ }^{a}$ ng/g of fat; interquartile range (IQR); visceral (vAT) and subcutaneous adipose tissue (scAT). Values are represented as median (IQR). Statistical analysis with MannWhitney and Kruskal-Wallis tests.

components had higher amounts of POPs ( $p$ 1/4 0.008). The analysis with individual POPs (see Supplementary material, Tables S4 and S5), did not fully replicate the results from the $\Sigma$ POP levels. Still, vAT methoxychlor levels were higher in patients with MetS and elevated tasting glucose and blood pressure, along with endosultan 11 tor elevated tasting glucose and Mlets. As tor $p, p^{\nu}$-DDE levels, they were higher both in vAT and scAT of patients with elevated fasting glucose. However, while not changing the directionality of the associations, when we adjusted the results for age, no significant associations were observed (see Supplementary material, Table S6). Nevertheless, the association with age remained significant in all models, supporting once more age as part of the causal pathway and the difficulty to isolate the independent effect of POPs.

Lastly, using the Framingham risk score to estimate the 10-year cardiovascular risk (Table 5), we observed a positive correlation with the vAT $\Sigma$ POP levels $\left(R_{S} 1 / 40.315, p \circ 0.01\right)$, as well as with total and scAT levels $\left(R_{S} 1 / 40.227, p \mathbf{O} 0.01\right.$ and $R_{S} 1 / 40.220, p \mathbf{0} 0.05$, respectively). Also in vAT, both methoxychlor and $\mathrm{HCH}$ lindane strongly correlated with CVD risk $\left(R_{S} 1 / 40.447, p 00.01\right.$ and

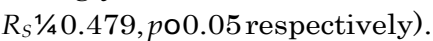

\subsection{Putative relation between POPs concentration and weight loss depending on age group}

In order to explore the putative influence of POPs in the success of weight loss, the evaluation of BMI variation 12 months after surgery was addressed (Fig. 1). Older subjects (46-65 years) had, in addition to higher preoperative $\Sigma$ POP levels (total, vAT and scAT), a significantly smaller reduction of BMI after 12 months (19-45 years, $12.570 .6 \mathrm{~kg} / \mathrm{m}^{2} ; 46-65$ years, $9.770 .5 \mathrm{~kg} / \mathrm{m}^{2}$; $p$ O 0.01$)$.

\section{Discussion}

In this study we assessed the distribution of several POPs in human AT of an obese population, and subsequently its association
Table 5

Spearman correlation coefficients $\left(R_{S}\right)$ of the 10-year estimate of cardiovascular risk (Framingham risk score) and the median levels of persistent organic pollutants (POPs)

\begin{tabular}{|c|c|c|c|c|c|c|}
\hline \multirow[t]{2}{*}{ POPs } & \multicolumn{3}{|l|}{ vAT } & \multicolumn{2}{|l|}{ scAT } & \multirow[b]{2}{*}{$p$ Value } \\
\hline & $n$ & Rs & $p$ Value & $n$ & $R_{s}$ & \\
\hline$\Sigma \mathrm{HCH}$ & 127 & 0.064 & 0.473 & 121 & 0.145 & 0.113 \\
\hline HCH Lindane & 37 & $0.479^{\mathrm{nn}}$ & 0.003 & 25 & 0.188 & 0.369 \\
\hline $\mathrm{HCB}$ & 13 & -0.027 & 0.929 & 12 & 0.042 & 0.897 \\
\hline Aldrin & 27 & -0.148 & 0.460 & 25 & -0.036 & 0.864 \\
\hline Dieldrin & 25 & 0.351 & 0.085 & 19 & 0.369 & 0.120 \\
\hline Endrin & 4 & & & 2 & & \\
\hline Endosulfan I & 12 & 0.336 & 0.286 & 5 & & \\
\hline Endosulfan II & 41 & 0.184 & 0.248 & 18 & 0.061 & 0.810 \\
\hline TCDD & 3 & & & 5 & & \\
\hline Methoxychlor & 87 & $0.447^{\mathrm{nn}}$ & $\boldsymbol{r} 0.001$ & 26 & -0.132 & 0.522 \\
\hline$\Sigma \mathrm{DDT} / \mathrm{DDE} / \mathrm{DDD}$ & 70 & 0.128 & 0.291 & 70 & 0.142 & 0.240 \\
\hline$o, p^{0}-\mathrm{DDT}$ & 13 & 0.077 & 0.803 & 14 & 0.495 & 0.072 \\
\hline$p, p^{0}-\mathrm{DDE}$ & 39 & 0.276 & 0.089 & 44 & 0.296 & 0.051 \\
\hline$p, p^{0}-\mathrm{DDD}$ & 19 & -0.223 & 0.359 & 14 & 0.103 & 0.725 \\
\hline$\Sigma$ POPs per tissue & 133 & $0.315^{\mathrm{nn}}$ & $r 0.001$ & 131 & $0.220^{n}$ & 0.012 \\
\hline Total $\Sigma$ POPs & 137 & $0.277^{\mathrm{nn}}$ & 0.001 & & & \\
\hline
\end{tabular}

Visceral (vAT) and subcutaneous adipose tissue (scAT). Statistical analysis with Spearman's correlation

$$
{ }^{\mathrm{nn}} \mathrm{p} 00.01 \text {. }
$$

with metabolic comorbidities, unravelling a putative involvement in the MetS. For this purpose, we analysed a sample of obese patients undergoing bariatric surgery. An important and novel evaluation was carried in this study, since by analysing two AT depots we were able to observe a dissimilar POPs distribution. Despite the accepted different metabolic properties of vAT and scAT (Freedland, 2004; Alessi et al., 1997), their storage propensity for these compounds was still not fully explored. Several studies admit that the distribution was similar in the two AT, offering the possibility of extrapolation from only one of the tissues (Kim et al., 2011; Arrebola et al., 2010). However other authors point out the 
A
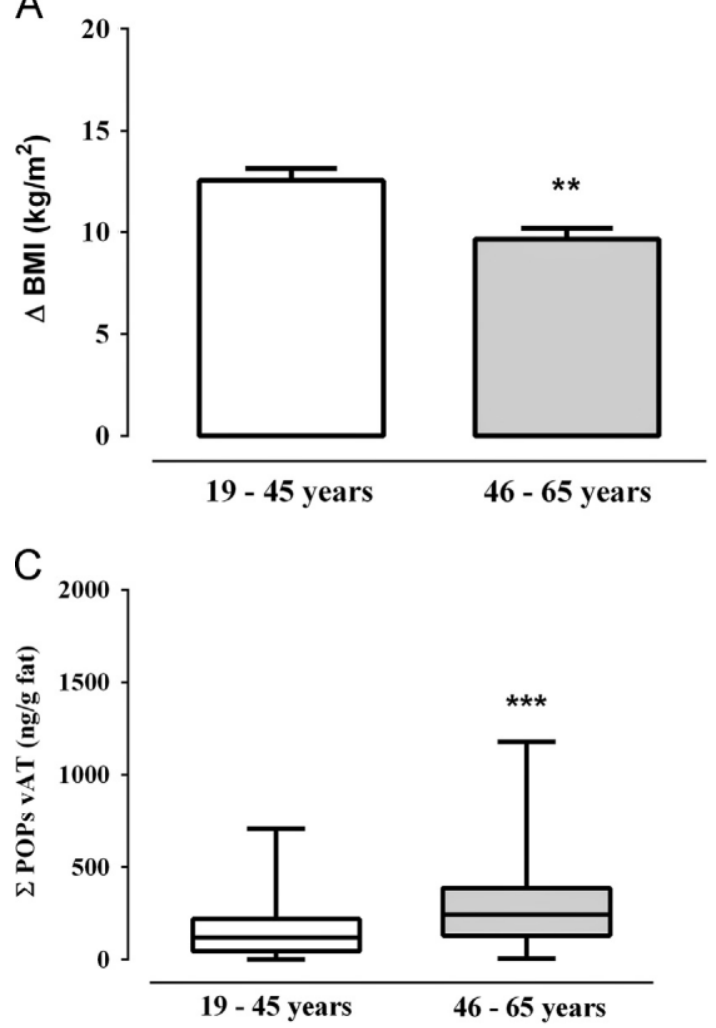

$\mathrm{B}$
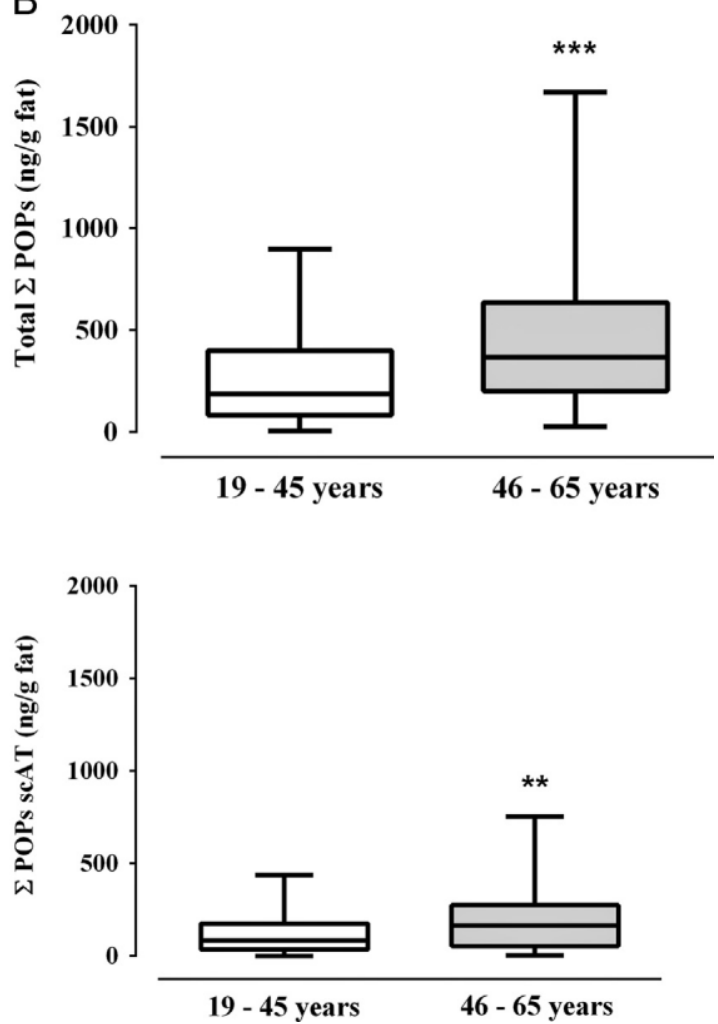

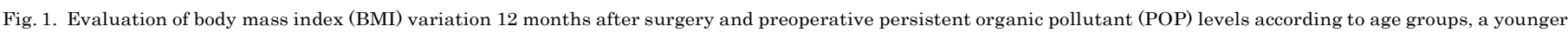

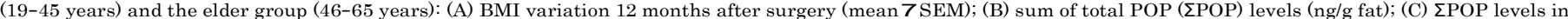

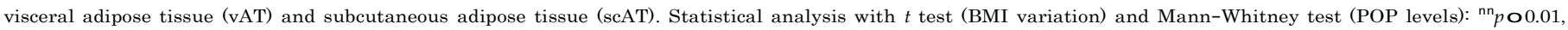
${ }^{\mathrm{nnn}} \mathrm{p}$ O 0.001 .

importance of a comprehensive evaluation of the heterogeneity of POPs distribution (La Merrill et al., 2013), however the current studies are still insufficient mostly due to the normal methodological restraints posed by this type of research (Malarvannan et al., 2013; Kim et al., 2014). The knowledge that the distribution of POPs is different between vAT and scAT highlights the importance of being cautious when making extrapolations, but also that we could be missing distinct metabolic effects. Furthermore, these results could also help explain, at least in part, the different metabolic profiles of vAT and scAT.

Another important observation was that virtually all subjects had detectable quantities of these pollutants in the AT. So, considering the $\Sigma$ POP levels, despite with equal percentage of detection $(96.3 \%)$ and positive correlations between vAT and scAT levels, the concentration was significantly higher in vAT. This result is relevant since vAT is held as an highly metabolic active tissue and apparently more susceptible to lipolysis and consequently to POPs release (Alessi et al., 1997; Roos et al., 2013).

We also addressed the relationship between POP levels and the clinical and biochemical markers at baseline, not forgetting the putative effect of differences in vAT and scAT. Our study subjects were already a risk population for the MetS development, since they were morbidly obese patients undergoing bariatric surgery, a metabolic surgery, due to its contribution to effective resolution or great improvement of comorbidity risk factors, in addition to weight loss. Despite this fact, there is still no clear explanation why some of these patients develop the common comorbidities of obesity and others do not (Freedland, 2004), and the mechanisms responsible for differences in weight losses. First of all, we showed a strong positive correlation of age with $\Sigma$ POP levels (total, vAT and scAT), an evaluation of the overall burden of POPs. This association can be a result of the lipophilic and bioaccumulative nature of POPs (Arrebola et al., 2010; Dirinck et al., 2011), corroborated by the same positive relation with years of obesity evolution, or a cohort effect, since older patients may have been more exposed to these compounds before they were banned. Another important observation confirmed by our data was that the $\Sigma$ POP levels related positively with glucose metabolism and blood pressure parameters, namely HbA1c and systolic blood pressure, comparable with results from other studies (Lee et al., 2007; Turyk et al., 2009). Moreover, scAT levels also correlated with HOMA-IR (indicator of insulin resistance) and diastolic blood pressure. Once again, the $\Sigma$ POP levels in vAT seems to be more representative of total levels. Interestingly, these results showed a positive relation between POPs concentrations and glucose metabolism or blood pressure parameters. However no relation was found with anthropometric parameters and lipid markers, probably based in the fact that obesity is already installed. Nevertheless, the association between BMI and POP levels is also still somehow controversial (Dirinck et al., 2011).

Assuming that these POPs alter some MetS components, we assessed the relationship between POP levels and the prevalence of individual metabolic abnormalities and MetS. Of all patients, approximately $65.8 \%$ had MetS, demonstrating that even in morbidly obese patients there are differences in metabolic abnormalities and MetS prevalence. Substantiating the previous results, we observed that POP levels either in total or both AT types tended to be higher in those subjects with evidence of metabolic dysfunction. This pattern was particularly evident in vAT, where adding to the significant difference in patients with elevated fasting glucose, the same tended to be true for elevated blood pressure and MetS itself. Nevertheless, the subjects with elevated fasting glucose had significantly higher POP levels regardless the considered AT depot. These results were similar as those described by Lee et al. (2011), 
where simultaneous exposure to various POPs contributed to development of obesity, dyslipidaemia, T2DM and CVD. Considering that these individuals were all obese, we can speculate that POPs exposure may contribute to these dysmetabolism features, evidence supported by the higher vAT $\Sigma$ POP levels in patients with increased aggregation of MetS components. Likewise, possibly even more relevant in the prediction of the metabolic dysfunction effects, the evaluation of cardiovascular risk within 10 years through the Framingham score corroborated the association of high concentrations of POPs with worse CVD prognosis, particularly considering the vAT. Indeed, a recent study regarding the possible relation of POPs in plasma with variation in the prevalence of metabolic risk among obese individuals, corroborates the pertinence of our results (Gauthier et al., 2014). However, we explore POPs present in AT and as highlighted by La Merrill et al. (2013), AT is unequivocally a target of POPs and experimental research is confirming their relation with metabolic diseases and diabetes.

Regarding individual POPs, we observed distinct behaviours. The compounds, $\Sigma \mathrm{HCH}, p, p^{0}-\mathrm{DDE}, p, p^{0}-\mathrm{DDD}$ and $\Sigma \mathrm{DDT} / \mathrm{DDE} / \mathrm{DDD}$, had a similar distribution to $\Sigma$ POPs. The levels of the most ubiquitous, $\Sigma \mathrm{HCH}$, also showed a strong positive correlation between vAT and scAT, and along with HCH lindane were positively correlated with dysglycaemia and hypertension, the levels of the last in vAT being also strongly correlated with CVD risk. Regarding DDT and its metabolites, there was no correlation between levels in vAT and scAT, but again the concentration in vAT was higher. The main contribution to the overall contamination with this group of compounds came from $p, p^{0}$-DDE, probably deriving from dietary exposure or from $o, p^{0}$-DDT metabolism, even after its use was banned in Portugal since 1988 (Fernandes et al., 2011; Correia-Sa et al., 2012). As suggested in the literature (Turyk et al., 2009; Lee et al., 2011), $p, p^{0}$-DDE is closely correlated with glucose metabolism impairment, which according to our results seems to be more influenced by their presence in vAT.

Moreover, the pesticides methoxychlor and endosulfan II had a different distribution pattern, with no differences in concentrations between tissues, but with higher percentage of positive samples in vAT. Methoxychlor, introduced with the intent of replacing DDT as a pesticide and recently also banned, was mainly detected in vAT from which its levels were correlated with worst glucose metabolism and lipid profile markers, plus cell damage markers and plasmatic urea. These relations support the prevalence of metabolic abnormalities (elevated fasting glucose and blood pressure) and MetS, besides a strong correlation with CVD risk. In turn, higher levels of endosulfan II in vAT were present in patients with elevated fasting glucose and MetS. Finally, with similar low percentages of detection between tissues, we observed a higher concentration of HCB, aldrin and dieldrin in scAT. In brief, despite the similarity with the overall relations observed in the $\Sigma$ POPs, the analysis of individual POPs did not fully replicate them, differing between POPs and tissues, emphasizing the dissimilarity between analysing one compound alone or their mixture, an important discussion in current environmental health research. Adding to the relations with glucose metabolism and hypertension markers, we also observed a relationship with adiposity and lipid profile markers, as well as cell damage and inflammatory markers in plasma.

This study also explored the relation between POP levels and adipocyte size. Obesity occurs by adipocyte hypertrophy or hyperplasia. Hypertrophy seems to be the initial steps towards adipocyte cell dysfunction (Monteiro, 2009; Monteiro et al., 2006) and POPs action on these mechanisms may promote their dysregulation (Grun and Blumberg, 2009; Wada et al., 2007). Our data did not reveal a correlation between the $\Sigma$ POP levels and adipocyte size from the corresponding tissue, probably because we analysed an obese population, and adipocytes are at the limit of lipid accumulation (Tan and Vidal-Puig, 2008; Virtue and Vidal-Puig, 2010). Additionally, recent studies reported that body weight change can affect serum and AT concentrations of POPs, suggesting that release of pollutants from AT could be related to increased lipolysis and therefore also associated with the magnitude of weight loss (Hue et al., 2006; Imbeault et al., 2001). In severely obese, as in other people, some are more successful in losing weight than others (Picot et al., 2009). In this study, the older subjects had a significantly smaller reduction of BMI after 12 months, in accordance with observations showing that patients' age negatively associates with success in weight loss after bariatric surgery (Scozzari et al., 2012; Faria et al., 2014). Interestingly, in these subjects, we also observed higher preoperative $\Sigma$ POP levels. Apparently, these results are compatible with a relationship between severity of dysmetabolism and resistance to weight loss and high POPs concentration, with vAT as a better representative of the overall effect. Despite preliminary, these results suggest an interesting association of surgery outcome success prediction, worthy of further research expanding to other outcome parameters.

We acknowledge that the present study is not without limitations: (i) the patients were at the "end-of-line" of obesity treatment; (ii) lack of complementary analyses of plasma POP levels. Notwithstanding, our study has significant assets regarding the large sample size; the analyses of two different AT depots, the main accumulation site and probably the most affected tissue; and the possibility to evaluate weight loss after surgery. These assets allowed us a better understanding of POP effects on metabolic abnormalities.

\section{Conclusion}

In conclusion, the fact that almost all AT samples had detectable levels of POPs provides ample reason for concern about the possible health effects of these compounds, even in countries with stricter regulations such as Portugal, under European legislation. Our study gives an important contribution for the elucidation of the dissimilar POPs storage capability of two metabolic distinct AT (vAT and scAT), where vAT appears more affected, particularly relevant when evaluating their metabolic impact. Furthermore, we observed a positive correlation between POP levels and metabolic abnormalities, namely with dysglycaemia and high blood pressure components of the MetS and most importantly with cardiovascular risk, with some relevance for vAT. Our sample of obese subjects allowed us to highlight the importance of POPs in the metabolic dysregulation despite the presence of obesity, shifting the focus to their metabolic effects and not only for its recognition as environmental obesogens. Furthermore, AT POP levels could be a possible predictor of unsuccessful weight loss in obese patients, worthy of further research. These results underline the need for Portuguese, as well as global, public health authorities to evaluate the extent of human exposure to environmental contaminants and lifestyle factors associated with the development of metabolic abnormalities.

\section{Funding}

FCT (Fundo Social Europeu, Programa Operacional Potencial Humano da EU (POPH); PEst-OE/SAU/UI0038/2011; SFRH/BD/ 46640/2008, SFRH/BD/47200/2008, SFRH/BD/64691/2009, SFRH/ BD/78367/2011, SFRH/BPD/75294/2010; and SFRH/BPD/40110/ 2007) and Projectos de Investigação na Pré-graduação 2010, UP150. No competing financial interests to declare. 


\section{Human ethics committee}

The participation of the human subjects did not occur until after informed consent was signed and study protocol was approved by the S. João Hospital's Ethics Committee (Porto, Portugal).

\section{Appendix A. Supplementary material}

Supplementary data associated with this article can be found in the online version at http://dx.doi.org/10.1016/j.envres.2014.05.026.

\section{References}

Alberti, KG, Eckel, RH, Grundy, SM, Zimmet, PZ, Cleeman, JI, Donato, KA, et al., 2009. Harmonizing the metabolic syndrome: a joint interim statement of the International Diabetes Federation Task Force on Epidemiology and Prevention; National Heart, Lung, and Blood Institute; American Heart Association; World Heart Federation; International Atherosclerosis Society; and International Association for the Study of Obesity. Circulation, 120; , pp. 1640-1645.

Alessi, MC, Peiretti, F, Morange, P, Henry, M, Nalbone, G, Juhan-Vague, I., 1997. Production of plasminogen activator inhibitor 1 by human adipose tissue: possible link between visceral fat accumulation and vascular disease. Diabetes 46 (5), 860-867.

Arrebola, JP, Fernandez, MF, Porta, M, Rosell, J, de la Ossa, RM, Olea, N, et al., 2010. Multivariate models to predict human adipose tissue PCB concentrations in Southern Spain. Environ. Int. 36 (7), 705-713.

Baillie-Hamilton, PF., 2002. Chemical toxins: a hypothesis to explain the global obesity epidemic. J. Altern. Complement. Med. 8 (2), 185-192.

Correia-Sa, L, Fernandes, VC, Carvalho, M, Calhau, C, Domingues, VF, Delerue-Matos, C., 2012. Optimization of QuEChERS method for the analysis of organochlorine pesticides in soils with diverse organic matter. J. Sep. Sci. 35 (12), 1521-1530.

D'Aorostino Sr, RB, Vasan, RS, Pencina, MJ, Wolf, PA, Cobain, M, Massaro, JM, et al., 2008. General cardiovascular risk profile for use in primary care: the Framingham Heart Study. Circulation 117 (6), 743-753.

Dirinck, E, Jorens, PG, Covaci, A, Geens, T, Roosens, L, Neels, H, et al., 2011. Obesity and persistent organic pollutants: possible obesogenic effect of organochlorine pesticides and polychlorinated biphenyls. Obesity (Silver Spring) 19 (4), 709714 .

Eurostat Regional Yearbook 2012, Publications Office of the European Union. Luxembourg, 2012.

Faria, G, Pestana, D, Preto, J, Guimaraes, JT, Taveira-Gomes, A, Calhau, C, 2014. Age and weight loss after bariatric surgery: cause or consequence? Comment on Contreras JE, Santander C, Court I, Bravo J. Correlation Between Age And Weight Loss After Bariatric Surgery. Obesity Surgery 2013; 23(8):1286-9. Obes. Surg. 24 (5), 824 .

Fernandes, VC, Domingues, VF, Mateus, N, Delerue-Matos, C., 2011. Organochlorine pesticide residues in strawberries from integrated pest management and organic farming. J. Agric. Food Chem. 59 (14), 7582-7591.

Fernandes, VC, Pestana, D, Monteiro, R, Faria, G, Meireles, M, Correia-Sa, L, et al., 2012. Optimization and validation of organochlorine compounds in adipose tissue by SPE-gas chromatography. Biomed. Chromatogr. 26 (12), 1494-1501.

Freedland, ES., 2004. Role of a critical visceral adipose tissue threshold (CVATT) in metabolic syndrome: implications for controlling dietary carbohydrates: a review. Nutr. Metab. (Lond) 1 (1), 12.

Friedewald, WT, Levy, RI, Fredrickson, DS., 1972. Estimation of the concentration of low-density lipoprotein cholesterol in plasma, without use of the preparative ultracentrifuge. Clin. Chem. 18 (6), 499-502.

Gauthier MS, Rabasa-Lhoret R, Prud'homme D, Karelis AD, Geng D, van Bavel B et al The metabolically healthy but obese phenotype is associated with lower plasma levels of persistent organic pollutants as compared to the metabolically abnormal obese phenotype. J. Clin. Endocrinol. Metab. 2014: jc20133935.

Grun, F, Blumberg, B., 2006. Environmental obesogens: organotins and endocrine disruption via nuclear receptor signaling. Endocrinology 147 (6 Suppl), S50-S55.

Grun, F, Blumberg, B., 2009. Endocrine disrupters as obesogens. Mol. Cell. Endocrinol. 304 (1-2), 19-29.

Hue, O, Marcotte, J, Berrigan, F, Simoneau, M, Dore, J, Marceau, P, et al., 2006. Increased plasma levels of toxic pollutants accompanying weight loss induced by hypocaloric diet or by bariatric surgery. Obes. Surg. 16 (9), 1145-1154.

Imbeault, P, Chevrier, J, Dewailly, E, Ayotte, P, Despres, JP, Tremblay, A, et al., 2001. Increase in plasma pollutant levels in response to weight loss in humans is related to in vitro subcutaneous adipocyte basal lipolysis. Int. J. Obes. Relat. Metab. Disord. 25 (11), 1585-1591.

Instituto Nacional de Estatística, 2011. Classificação Portuguesa das Profissões de, 2010. Lisboa, Eurostat.

Kim, KS, Lee, YM, Kim, SG, Lee, IK, Lee, HJ, Kim, JH, et al., 2014. Associations of organochlorine pesticides and polychlorinated biphenyls in visceral vs. subcutaneous adipose tissue with type 2 diabetes and insulin resistance. Chemosphere 94, 151-157.
Kim, MJ, Marchand, P, Henegar, C, Antignac, JP, Alili, R, Poitou, C, et al., 2011. Fate and complex pathogenic effects of dioxins and polychlorinated biphenyls in obese subjects before and after drastic weight loss. Environ. Health Perspect. 119 (3), 377-383.

Lee, DH, Lee, IK, Porta, M, Steffes, M, Jacobs Jr., DR, 2007. Relationship between serum concentrations of persistent organic pollutants and the prevalence of metabolic syndrome among non-diabetic adults: results from the National Health and Nutrition Examination Survey 1999-2002. Diabetologia 50 (9), 1841-1851.

Lee, DH, Steffes, MW, Sjodin, A, Jones, RS, Needham, LL, Jacobs Jr., DR, 2011. Low dose organochlorine pesticides and polychlorinated biphenyls predict obesity, dyslipidemia, and insulin resistance among people free of diabetes. PLoS One 6 (1), e15977.

Lee, H., 2007. Relationship between serum concentrations of persistent organic pollutants and the prevalence of metabolic syndrome among non-diabetic adults: results from the National Health and Nutrition Examination Survey 1999-2002. Diabetologia 50, 1841-1851.

Li, QQ, Loganath, A, Chong, YS, Tan, J, Obbard, JP., 2006. Persistent organic pollutants and adverse health effects in humans. J. Toxicol. Environ. Health A 69 (21), 19872005.

Malarvannan, G, Dirinck, E, Dirtu, AC, Pereira-Fernandes, A, Neels, H, Jorens, PG, et al., 2013. Distribution of persistent organic pollutants in two different fat compartments from obese individuals. Environ. Int. 55, 33-42.

La Merrill, M, Emond, C, Kim, MJ, Antignac, JP, Le Bizec, B, Clement, K, et al., 2013. Toxicological function of adipose tissue: focus on persistent organic pollutants. Environ. Health Perspect. 121 (2), 162-169.

Monteiro, R., 2009. Chronic inflammation in the metabolic syndrome: emphasis on adipose tissue. In: Soares, R, Costa, C (Eds.), Oxidative Stress, Inflammation and Angiogenesis in the Metabolic Syndrome. Springer, The Netherlands, pp. 65-84.

Monteiro, R, de Castro, PM, Calhau, C, Azevedo, I, 2006. Adipocyte size and liability to cell death. Obes. Surg. 16 (6), 804-806.

Neel, BA, Sargis, RM., 2011. The paradox of progress: environmental disruption of metabolism and the diabetes epidemic. Diabetes 60 (7), 1838-1848.

Newbold, RR, Padilla-Banks, E, Jefferson, WN, Heindel, JJ., 2008. Effects of endocrine disruptors on obesity. Int. J. Androl. 31 (2), 201-208.

Ozonoff, D, Aschengrau, A, Coogan, P., 1994. Cancer in the vicinity of a department of defense superfund site in Massachusetts. Toxicol. Ind. Health 10 (3), 119-141.

Palaniappan, L, Carnethon, MR, Wang, Y, Hanley, AJ, Fortmann, SP, Haffner, SM, et al., 2004. Predictors of the incident metabolic syndrome in adults: the Insulin Resistance Atherosclerosis Study. Diabetes Care 27 (3), 788-793.

Picot, J, Jones, J, Colquitt, JL, Gospodarevskaya, E, Loveman, E, Baxter, L, et al., 2009. The clinical effectiveness and cost-effectiveness of bariatric (weight loss) surgery for obesity: a systematic review and economic evaluation. Health Technol. Assess. 13 (41), 215-357 (1-190).

Preis, SR, Massaro, JM, Robins, SJ, Hoffmann, U, Vasan, RS, Irlbeck, T, et al., 2010. Abdominal subcutaneous and visceral adipose tissue and insulin resistance in the Framingham heart study. Obesity (Silver Spring) 18 (11), 2191-2198.

Roos, V, Ronn, M, Salihovic, S, Lind, L, Bavel, B, Kullberg, J, et al., 2013. Circulating levels of persistent organic pollutants in relation to visceral and subcutaneous adipose tissue by abdominal MRI. Obesity (Silver Spring) 21 (2), 413-418.

Scozzari, G, Passera, R, Benvenga, R, Toppino, M, Morino, M., 2012. Age as a longterm prognostic factor in bariatric surgery. Ann. Surg. 256 (5) (724-8; discussion 728-9).

Sjoberg Lind, Y, Lind, PM, Salihovic, S, van Bavel, B, Lind, L., 2013. Circulating levels of persistent organic pollutants (POPs) are associated with left ventricular systolic and diastolic dysfunction in the elderly. Environ. Res. 123, 39-45.

Tan CY, Vidal-Puig A, 2008, Adipose tissue expandability: the metabolic problems of obesity may arise from the inability to become more obese. Biochem Soc Trans 36(Pt 5): 935-940.

Turyk, M, Anderson, HA, Knobeloch, L, Imm, P, Persky, VW., 2009. Prevalence of diabetes and body burdens of polychlorinated biphenyls, polybrominated diphenyl ethers, and $p, p^{0}$-diphenyldichloroethene in Great Lakes sport fish consumers. Chemosphere 75 (5), 674-679.

Valera, B, Jorgensen, ME, Jeppesen, C, Bjerregaard, P., 2013. Exposure to persistent organic pollutants and risk of hypertension among Inuit from Greenland. Environ. Res. 122, 65-73.

Vandenberg, LN, Colborn, T, Hayes, TB, Heindel, JJ, Jacobs Jr., DR, Lee, DH, et al., 2012. Hormones and endocrine-disrupting chemicals: low-dose effects and nonmonotonic dose responses. Endocr. Rev. 33 (3), 378-455.

Vandenberg, LN, Colborn, T, Hayes, TB, Heindel, JJ, Jacobs Jr., DR, Lee, DH, et al., 2013. Regulatory decisions on endocrine disrupting chemicals should be based on the principles of endocrinology. Reprod. Toxicol. 38C, 1-15.

Virtue, S, Vidal-Puig, A, 2010. Adipose tissue expandability, lipotoxicity and the metabolic syndrome-an allostatic perspective. Biochim. Biophys. Acta 1801 (3), 338-349.

Wada, K, Sakamoto, H, Nishikawa, K, Sakuma, S, Nakajima, A, Fujimoto, Y, et al., 2007. Life style-related diseases of the digestive system: endocrine disruptors stimulate lipid accumulation in target cells related to metabolic syndrome. J. Pharmacol. Sci. 105 (2), 133-137.

Wallace, TM, Levy, JC, Matthews, DR., 2004. Use and abuse of HOMA modeling. Diabetes Care 27 (6), 1487-1495. 